\title{
COMPORTAMENTOS ASSERTIVOS E DIMENSÕES DE PERFECCIONISMO EM ÁRBITROS NO ÂMBITO NACIONAL
}

\section{Regina Alves Thon}

Universidade Estadual de Maringá, Maringá, Paraná, Brasil.

Camila Rinaldi Bisconsini

Universidade Estadual de Maringá, Maringá, Paraná, Brasil.

\section{Pedro Paulo Deprá}

Universidade Estadual de Maringá, Maringá, Paraná, Brasil.

Amauri Aparecido Bássoli de Oliveira

Universidade Estadual de Maringá, Maringá, Paraná, Brasil.

\section{Lenamar Fiorese Vieira}

Universidade Estadual de Maringá, Maringá, Paraná, Brasil.

\section{Resumo}

O presente estudo teve como objetivo investigar a assertividade e o perfeccionismo dos árbitros de modalidades individuais. Participaram da pesquisa 67 árbitros de nível estadual e nacional, sendo 19 do judô e 47 da natação. Os instrumentos contemplam o Inventário Assertivo e a Escala Multidimensional de Perfeccionismo. Para análise dos dados foram utilizados os testes Kolmogorov-Smirnov, o teste " $U$ " de Mann-Whitney e ANOVA de medidas repetidas. Entre os árbitros prevaleceu o alto nível de comportamento assertivo, evidenciando características perfeccionistas de organização e padrões de realização pessoal. Concluímos que a assertividade e a organização foram evidenciadas nos árbitros, que demonstraram altos padrões de realização pessoal na função que executam.

Palavras chave: Árbitros. Comportamentos. Natação. Judô.

\section{Introdução}

Os árbitros têm por função fazer com que as regras sejam cumpridas durante uma partida ou competição (GAMA, 1998). Dependendo da modalidade, existem um ou mais árbitros por competição, sendo que estes cumprem funções variadas. Durante a atuação esses profissionais têm o dever de 
cumprir todas as normas do esporte, sendo que qualquer infração ocorrida durante a competição necessita ser interpretada com rapidez e segurança.

O trabalho pertinente ao árbitro não é de fácil ação. De acordo com Silva, Rodriguez-Añez e Frómeta (2002, p.41), "O árbitro deve, praticamente, em um mesmo instante observar, constatar, interpretar, julgar e punir ou absolver um atleta, o que não é fácil e não é qualquer pessoa que consegue".

Para tanto, o árbitro precisa conhecer as regras e julgá-las com assertividade, precisão e com justiça, contudo, precisa estar em boas condições psicológicas para garantir uma boa atuação no momento da competição. Assim, considera-se essencial investigar aspectos do comportamento desses profissionais, no intuito de vislumbrar possíveis contribuições pontuais, no que diz respeito à sua atuação profissional na arbitragem.

Alguns estudos relacionados a árbitros de futebol, que se encontram nos campos da fisiologia e da psicologia, indicam que os árbitros que são submetidos à alta sobrecarga física e fisiológica sofrem interferência em seu desempenho. Alguns exemplos desses estudos são os de Silva e RodriguezAñez (2003), que identificaram parâmetros fisiológicos de árbitros assistentes; Pereira, Aladashvile e Silva (2006), que analisaram as causas que levam árbitros a desistirem da carreira de árbitro profissional; e Silva e Rech (2008), que descreveram o somatotipo e composição corporal de árbitros e árbitros assistentes da CBF (Confederação Brasileira de Futebol).

Poucos são os estudos publicados para a realidade brasileira na área da psicologia esportiva, e em especial no contexto da arbitragem. Esta pesquisa buscou preencher uma lacuna nesta área de estudos, investigando a assertividade e o perfeccionismo de árbitros de modalidades individuais que atuam e são responsabilizados pelo bom andamento da competição. Considerando que estas variáveis são intervenientes e fundamentais devido ao fato de essa função exigir atitudes honestas e elevados índices de acertos, não sendo o erro permitido.

Sobre a assertividade, ainda encontra-se dificuldade para localizar trabalhos que analisem o próprio conceito do termo. Entretanto, considerando que a ação de julgar e decidir com precisão é inerente ao trabalho do árbitro, torna-se relevante potencializar a produção de estudos que contribuam para uma ação assertiva diante de situações por vezes conturbadas, como uma competição esportiva.

Em relação ao perfeccionismo, Amaral et al. (2013) afirmam que este é um tema de interesse crescente, sendo entendido como um traço de personalidade pontuado pela busca da perfeição e de elevados padrões de desempenho acompanhados pela crítica excessiva do comportamento. Além disso, os autores afirmam que o perfeccionismo exerce um papel na resposta individual ao estresse psicossocial. Entende-se necessário investigar as di-

Pensar a Prática, Goiânia, v. 17, n. 3, p. 800-814, jul./set. 2014 
mensões do perfeccionismo no contexto da arbitragem pelo fato destes profissionais se encontrarem, frequentemente, em momentos de tensão enquanto atuam, sendo que precisam tomar decisões rápidas durante partidas esportivas que envolvem atletas em situação de competição.

Portanto, a preparação psicológica do árbitro tem que ser levada em consideração devido ao fato de esta função exigir o domínio de habilidades de julgamento dos comportamentos esportivos em um curto espaço de tempo, além do controle das condutas humanas que atuam no contexto desportivo (GAMA et al., 1998).

A opção de investigar modalidades individuais se destaca devido a estas apresentarem determinadas especificidades que precisam ser pontuadas. Segundo Gonçalves e Belo (2007, p. 303),

[...] atletas de esportes individuais apresentam maior nível de ansiedade do que os de equipes, especificamente na natação e no atletismo. Além disso, em esportes individuais os atletas não compartilham a responsabilidade, expondo-se sozinhos a uma avaliação direta dos expectadores, gerando uma pressão desproporcional à demonstração de excelência na performance.

Nesse sentido, um ponto a ser apresentado é a pressão que sofre o atleta de modalidade individual, o que faz com que o árbitro tenha grande responsabilidade pelo bom andamento da competição. Como afirma Rose Junior (2002, p. 25):

[...] o estresse competitivo tem muita relação com o momento da competição [...]. As questões relacionadas com a competência ou habilidades individuais são muito marcantes, o mesmo acontecendo com pessoas que são importantes no processo competitivo: técnico, árbitros (grifo nosso) e companheiros de equipe.

Assim, conhecer o contexto e as regras da modalidade é de fundamental importância para a atuação do árbitro, estes elementos podem interferir no sentimento e na ação do atleta durante a competição, sendo seu julgamento imprescindível para os resultados do competidor em questão. Assim, Pereira, Santos e Cillo (2007) apontam que um grande número de árbitros ressalta a importância de boas condições psicológicas para uma atuação adequada.

Em relação aos aspectos psicológicos, alguns estudos estão centrados na área do perfeccionismo, em diferentes contextos, incluindo o despor-

Pensar a Prática, Goiânia, v. 17, n. 3, p. 800-814, jul./set. 2014 
to e o exercício. Para Cruz, Varella e Cabanelas (2010, p. 1), "O estudo do perfeccionismo tem atraído o interesse de um número crescente de investigadores dos mais variados contextos e domínios, incluindo, naturalmente, os contextos desportivos".

Duas dimensões gerais e comuns são destacadas: os padrões pessoais (organização e preocupações com os erros); e as preocupações avaliativas (criticismo parental; expectativas parentais; dúvidas na ação). Os resultados do estudo de Oliveira et al. (2004) apontam que a combinação das dimensões de expectativas e críticas parentais elevadas podem ter efeitos negativos no traço de perfeccionismo.

Em relação ao comportamento assertivo, Cunha e Tourinho (2010) afirmam que a maior concentração de publicações sobre o assunto está situada nas décadas de 1970 e 80 . Portanto, nas últimas décadas, pesquisas em relação à assertividade são fundamentais para os estudos sobre comportamentos.

Entende-se necessário investigar o comportamento assertivo dos árbitros para buscar ampliar as reflexões acerca das formas específicas de expressar e de respeitar a si mesmo e aos outros, estimulando o respeito e a compreensão no contexto do esporte. A literatura aponta que o comportamento assertivo é aquele que promove a igualdade nas relações humanas e que permite agir de acordo com os próprios interesses, defendendo as posições, sem ansiedade, expressando sentimentos de maneira honesta e tranquila. O comportamento não assertivo remete às ações em que o indivíduo apresenta passividade e não se manifesta no momento adequado (ALBERT e EMMONS, 2008). Já o comportamento agressivo pode induzir ao erro devido à alta ansiedade no contexto esportivo.

Como exemplo, cabe destacar as colocações de Pereira, Aladashvile e Silva (2006, p. 191), ao afirmarem que "a incerteza de serem ou não escalados novamente gera forte pressão psicológica nos árbitros, que vão para o campo de jogo preocupando-se com outras questões além da aplicação das regras, o que pode comprometer sua atuação". Em estudo realizado por Levitan, Rangé e Nardi (2008), pontua-se que pessoas com baixa assertividade apresentam mais risco de desenvolver depressão do que os pacientes assertivos, fazendo-se necessário atentar para este fator comportamental.

Assim sendo, este estudo objetivou investigar o comportamento assertivo e as dimensões de perfeccionismo dos árbitros, nas modalidades individuais do judô e da natação. Especificamente, buscou-se identificar e comparar os níveis de assertividade e as dimensões de perfeccionismo dos árbitros em função da modalidade e do sexo, bem como avaliar as correlações das variáveis do comportamento assertivo com as dimensões de perfeccionismo dos árbitros.

Pensar a Prática, Goiânia, v. 17, n. 3, p. 800-814, jul./set. 2014 
As hipóteses conceituais do estudo foram: $\mathrm{H}_{1}=$ árbitros têm prevalência de comportamentos assertivos; $\mathrm{H}_{2}=$ comportamentos não assertivos apresentam correlação com o criticismo parental; $\mathrm{H}_{3}=$ comportamentos agressivos se correlacionam com dúvidas na ação e preocupação com os erros; $\mathrm{H}_{4}=$ árbitros apresentam diferenças nas dimensões do perfeccionismo e assertividade, quando comparados os sexos; H5= comportamentos não assertivos se correlacionam com o desajustamento.

\section{Materiais e Métodos}

\section{Sujeitos}

Foram selecionados 19 árbitros de judô e 48 de natação, de ambos os sexos, tendo como critério de escolha as modalidades esportivas em que o Brasil teve maior destaque nas duas últimas olimpíadas, quanto ao quadro de medalhas, acreditando que estes árbitros precisam frequentemente investir na sua formação profissional e aprimoramento de seus atributos pessoais.

Os dados foram coletados em eventos de natação estaduais e nacionais, com a participação de representantes dos diversos Estados brasileiros. Para o Judô foram selecionados árbitros que participaram de dois campeonatos do Estado do Paraná de diferentes categorias, eventos esses que também tiveram a presença de árbitros internacionais.

Os 67 árbitros apresentaram média de idade de 35,6 $\pm 10,4$ anos. Como critério de inclusão foram adotados os seguintes aspectos: (1) assinar o termo de consentimento livre e esclarecido; (2) preencher adequadamente os instrumentos; (3) atuar por um período mínimo de três anos na modalidade; (4) ser credenciado em sua respectiva federação e confederação.

O estudo está vinculado ao projeto institucional "Estudo dos Aspectos Psicológicos e Comportamentais Relacionados ao Contexto Esportivo" $\left(\right.$ Parecer $\left.n^{\circ} 339 / 2011^{1}\right)$.

\section{Instrumentos}

Os árbitros preencheram uma ficha de identificação que continha os seguintes dados: idade, tempo de atuação na modalidade, níveis de atuação, formação profissional e sexo. Posteriormente, foram respondidos o Inventário Assertivo e a Escala Multidimensional de Perfeccionismo.

\footnotetext{
1 Vinculado ao Departamento de Educação Física da Universidade Estadual de Maringá.
}

Pensar a Prática, Goiânia, v. 17, n. 3, p. 800-814, jul./set. 2014 
Para avaliar o nível de assertividade, utilizou-se o Inventário Assertivo de Albert \& Emmons $\left(2008^{2}\right)$, composto por 35 questões, o qual apresenta três dimensões do comportamento: assertivo (expressão honesta de sentimentos e a conquista de meta); não assertivo (sentimento de ansiedade, confusão e culpa); e agressivo (sentimento de ressentimento, frustração e rejeição). Utilizamos uma escala Likert de cinco pontos: $0=$ não ou nunca; $1=$ um pouco ou às vezes; $2=$ média; $3=$ muitas vezes; e $4=$ quase sempre ou inteiramente. Esse inventário apresentou um alto índice de confiabilidade $(\alpha=0,88)$.

Para avaliar o perfeccionismo, utilizou-se a Escala Multidimensional de Perfeccionismo (MPS) de Frost et al. (1990), validada para língua portuguesa por Serpa, Alves e Barreiros (2004). O instrumento é composto por 35 itens em uma escala Likert de cinco pontos, que variam de "discordo plenamente" (1) a "concordo plenamente" (5). Os resultados são classificados em seis sub-escalas: preocupações com os erros; padrões de realização pessoal; expectativas parentais; criticismo parental; dúvidas na ação; e organização.

Cada sub-escala é calculada a partir da média da somatória dos itens que a integram, podendo ainda calcular-se um "Índice de Perfeccionismo Global" a partir da somatória dos valores absolutos dos itens. Além disso, os autores indicam dois tipos de perfeccionismo a partir das dimensões do instrumento: 1) perfeccionismo ajustado ou normal - quando se encontram elevados valores nas subescalas "padrões de realização pessoal" e "organização" - e 2) perfeccionismo desajustado ou neurótico - quando se encontram elevados valores nas subescalas "preocupações com os erros", "dúvidas na ação" e "criticismo parental". Este instrumento apresentou um alto índice de confiabilidade $(\alpha=0,89)$.

\section{Coleta de dados}

Os pesquisadores entraram em contato com os diretores e coordenadores de arbitragem das federações e confederações das modalidades investigadas com o intuito de esclarecer os objetivos da pesquisa e pedir a autori-

2

Inventário Assertivo: cada questão predomina um tipo de comportamento. A Escala apresenta pontuação 4 que representa frequência máxima do comportamento que correspondente respectivamente à assertivo (16 questões), não assertivo (8 questões) ou agressivo (11). Somam-se os pontos atribuídos a cada categoria (assertivo, não assertivo e agressivo), e dividem-se os resultados respectivamente por $0.64 ; 0.32$ e 0.44 , obtendo os percentuais das chances de ser assertivo, não assertivo e agressivo.

Pensar a Prática, Goiânia, v. 17, n. 3, p. 800-814, jul./set. 2014 
zação dos mesmos para a realização do estudo. Após o contato foram agendadas as coletas nas competições, obedecendo ao calendário de cada modalidade. Os dados foram coletados no segundo semestre de 2012. Foram solicitadas as assinaturas do Termo de Consentimento Livre e Esclarecido (TCLE). Os questionários dos árbitros foram aplicados de duas formas: via e-mail ( $\mathrm{n}=10)$, aos árbitros nacionais indicados pelos coordenadores de arbitragem que não estavam presentes nos eventos onde ocorreram as coletas; e nas competições $(n=57)$, onde os questionários eram entregues aos responsáveis pela equipe de arbitragem, que entregavam posteriormente aos pesquisadores.

\section{Análise dos dados}

Para a análise da distribuição dos dados utilizou-se o teste Kolmogorov-Smirnov. Os dados não apresentaram distribuição normal, assim foram utilizados mediana e intervalo interquartílico para caracterização dos resultados. Para a comparação entre as características de perfeccionismo utilizouse, após a verificação da esfericidade das variâncias, a Anova de Medidas Repetidas, seguida do Post Hoc de Bonferroni. Para comparação entre os sexos aplicou-se o teste " $U$ ” de Mann-Whitney. Para a verificação da correlação entre as variáveis, utilizou-se o coeficiente de correlação de Spearman. A significância adotada foi $\mathrm{p}<0,05$.

\section{Resultados}

A Tabela 1 apresenta a mediana e o intervalo interquartil dos níveis do comportamento assertivo, não assertivo e agressivo dos árbitros brasileiros de natação e judô.

Tabela 1 - Mediana e quartis dos níveis de assertividade, não assertividade e agressividade dos árbitros de natação e judô

\begin{tabular}{ccc}
\hline DIMENSÕES & Md & Q1; Q3 \\
\hline Assertivo & 67,19 & 56,$25 ; 79,69$ \\
Não assertivo & 37,50 & 18,$75 ; 50,00$ \\
Agressivo & 31,82 & 22,$73 ; 40,00$ \\
\hline
\end{tabular}

Verifica-se (Tabela 1) destaque na dimensão de assertividade $(\mathrm{Md}=67,19)$ em relação a não assertividade $(\mathrm{Md}=37,50)$ e agressividade $(\mathrm{Md}=31,82)$. 
A Tabela 2 apresenta a comparação das características de perfeccionismo dos árbitros de natação e judô, do contexto esportivo brasileiro.

Tabela 2 - Comparação das características de perfeccionismo dos árbitros de natação e judô

\section{CARACTERÍSTICAS DE PERFECCIONISMO Md (Q1; Q3)}

1. Preocupação com erros $2,20(1,90 ; 2,60)^{\mathrm{a}}$

2. Dúvidas na ação $2,30(2,00 ; 2,80)^{b}$

3. Expectativas parentais $2,00(1,40 ; 2,60)^{\mathrm{a} / \mathrm{c}}$

4. Criticismo Parental $1,80(1,30 ; 2,00)^{\mathrm{a} / \mathrm{b} / \mathrm{c} / \mathrm{d}}$

5. Padrões de Realização Pessoal $3,40(3,00 ; 3,90)^{\mathrm{a} / \mathrm{b} / \mathrm{c} / \mathrm{d} / \mathrm{e}}$

6. Organização $4,00(3,50 ; 4,50)^{\mathrm{a} / \mathrm{b} / \mathrm{c} / \mathrm{d} / \mathrm{e}}$

*Diferença significativa - P<0,008 (Correção Post Hoc de Bonferroni). Houve diferença significativa entre: a) preocupação com os erros e criticismo parental, padrões de realização pessoal e organização; b) dúvidas na ação e criticismo parental, padrões de realização pessoal e organização; c) expectativas parentais e criticismo parental, padrões de realização pessoal e organização; d) criticismo parental, padrões de realização pessoal e organização; e) padrões de realização pessoal e organização.

A dimensão que teve a maior mediana entre as demais foi a organização $(\mathrm{Md}=4,00)$, e a menor foi o criticismo parental $(\mathrm{Md}=1,80)$.

A Tabela 3 apresenta a comparação do nível de assertividade e das dimensões de perfeccionismo dos árbitros brasileiros de natação e judô em função do sexo.

Tabela 3 - Comparação do nível de assertividade e dimensões de perfeccionismo dos árbitros de natação e judô quanto ao sexo

\begin{tabular}{lcccc}
\hline \multirow{2}{*}{ VARIÁVEIS } & MASCULINO & FEMININO & \multirow{2}{*}{ P } \\
\cline { 2 - 3 } Assertividade & Md (Q1; Q3) & Md (Q1; Q3) & \\
Assertivo & $65,63(58,59 ; 78,83)$ & $68,75(54,69 ; 77,34)$ & 0,74 \\
Não-assertivo & $25,00(18,75 ; 37,50)$ & $21,88(18,75 ; 40,62)$ & 0,48 \\
Agressivo & $22,73(17,61 ; 31,82)$ & $22,73(20,45 ; 32,95)$ & 0,24
\end{tabular}

\section{Perfeccionismo}




$\begin{array}{lccc}\begin{array}{l}\text { Preocupação com } \\ \text { erros }\end{array} & 2,10(1,80 ; 2,45) & 2,20(1,95 ; 2,65) & 0,23 \\ \text { Dúvidas na ação } & 2,30(1,95 ; 2,80) & 2,30(2,00 ; 3,00) & 0,46 \\ \text { Expectativas parentais } & 1,80(1,40 ; 2,65) & 2,20(1,80 ; 2,60) & 0,19 \\ \text { Criticismo Parental } & 1,80(1,22 ; 2,00) & 2,00(1,50 ; 2,15) & 0,17 \\ \text { Realização Pessoal } & 3,40(2,97 ; 3,90) & 3,30(3,10 ; 3,75) & 0,54 \\ \text { Organização } & 4,10(3,30 ; 4,70) & 4,00(3,40 ; 4,20) & 0,21 \\ \text { Ajustado } & 49,00(42,00 ; 54,00) & 48,00(43,00 ; 50,50) & 0,29 \\ \text { Desajustado } & 36,00(28,75 ; 40,00) & 37,00(34,00 ; 41,00) & 0,15 \\ \text { Índice Global } & 93,00(81,00 ; 104,50) & 97,00(87,00 ; 104,00) & 0,51\end{array}$
$\mathrm{p}<0,05$.

Quando comparadas as variáveis de assertividade e perfeccionismo em relação ao sexo (Tabela 3), não houve diferença estatisticamente significativa entre nenhuma das variáveis.

A Tabela 4 apresenta a correlação entre as características de perfeccionismo e o comportamento assertivo, não assertivo e agressivo dos árbitros.

Tabela 4 - Correlação dos níveis de assertividade com as dimensões de perfeccionismo dos árbitros brasileiros de natação e judô

\begin{tabular}{|c|c|c|c|}
\hline $\begin{array}{l}\text { CARACTERÍSTICAS } \\
\text { PERFECCIONISMO }\end{array}$ & DI Assertivo & Não assertivo & Agressivo \\
\hline$\overline{\text { Preocupação com erros }}$ & 0,16 & $\mathbf{0 , 3 4 * *}$ & $\mathbf{0 , 3 1}$ *** \\
\hline Dúvidas na ação & $-0,11$ & 0,29 & $-0,38$ \\
\hline Expectativas parentais & 0,21 & 0,20 & 0,10 \\
\hline Criticismo Parental & 0,00 & 0,25 & 0,11 \\
\hline Realização Pessoal & 0,06 & 0,23 & 0,12 \\
\hline Organização & 0,00 & 0,00 & $-0,13$ \\
\hline Ajustado & 0,33 & 0,16 & 0,00 \\
\hline Desajustado & 0,70 & $\mathbf{0 , 3 5} * *$ & 0,20 \\
\hline Índice Global & 0,12 & $\mathbf{0 , 3 3} * *$ & 0,17 \\
\hline
\end{tabular}

**Correlação significativa - $\mathrm{p}<0,05$.

Foram encontradas correlações entre preocupação com os erros e comportamento não assertivo $(\mathrm{r}=0,34)$; entre preocupação com os erros e comportamento agressivo $(\mathrm{r}=0,31)$; entre comportamento não assertivo com o desajustamento $(r=0,35)$ e com o índice global $(r=0,33)$. 


\section{Discussões}

Durante a investigação, o comportamento que prevaleceu foi o assertivo (Tabela 1). Essa é a expressão direta em que a pessoa manifesta suas necessidades ou preferências de forma clara e consistente nas emoções e opiniões, sem ansiedade indevida ou excessiva, e sem ser hostil com o outro. Nesse aspecto, Gama et al. (1998) destacam que a firmeza é uma qualidade imprescindível para os árbitros, como um atributo para convencer os competidores sobre a sua autoridade e para ajudar no controle das situações conflituosas que podem se manifestar entre os participantes na competição, confirmando a hipótese $\mathrm{H}_{1}$.

Em relação ao perfeccionismo (Tabela 2), os maiores escores estão nas características de organização $(\mathrm{Md}=4,00)$, seguidas dos padrões de realização pessoal $(\mathrm{Md}=3,40)$, e o menor escore encontrado foi na característica de criticismo parental $(\mathrm{Md}=1,80)$. A organização é uma dimensão importante e reflete na característica de destaque para a atuação dos árbitros que precisam manter a ordem no contexto das competições, mantendo uma boa realização pessoal no que fazem. A dimensão criticismo parental teve menor mediana entre as demais dimensões, demonstrando que esta tem pouca influência nos árbitros deste nível (estadual e nacional) em suas ações no decorrer das competições.

O perfeccionismo ajustado apresentou maiores escores quando comparados ao desajustado (Tabela 3), característica esta imprescindível à atuação dos árbitros. De acordo com Stirling e Kerr (2006), o perfeccionismo normal (ajustado) pode ser um atributo positivo que reflete padrões saudáveis de comportamento no contexto da arbitragem.

Sagar e Stoeber (2009) concluíram que pode existir o desejo de ser perfeito e evitar falhas envolvidas com questões cognitivas complexas, o que pode levar a determinados comportamentos, como o desajustamento (Tabela 4). Tal afirmação vai ao encontro da correlação significativa entre não assertividade e desajustamento $(r=0.35)$. Este resultado demonstra que a não assertividade tende a ser prejudicial para a arbitragem, interferindo nas ações tomadas no momento da competição e gerando dúvidas e erros no momento do julgamento das regras.

O desajustamento quando correlacionado com o comportamento não assertivo pode ser um problema na atuação do árbitro, pois se essa ação torna-se frequente, o árbitro tende a apresentar um desajuste no contexto. Quanto maior a preocupação com os erros, maior também é a probabilidade de se ter comportamentos não assertivos e agressivos. De acordo com Hinnen (2008), pessoas que mantém comportamentos não assertivos possuem

Pensar a Prática, Goiânia, v. 17, n. 3, p. 800-814, jul./set. 2014 
altos níveis de tensão social. Esta tensão pode ser prejudicial nas ações do árbitro, tornando-o passivo e com dificuldade de tomar decisão no momento adequado.

O comportamento não assertivo dos árbitros (Tabela 04) teve correlação positiva com a preocupação com os erros $(\mathrm{r}=0,34)$, e com o índice global $(\mathrm{r}=0,33)$. Indivíduos que apresentam comportamentos não assertivos geralmente adotam atitudes de passividade, se preocupando muito com os erros, pensam na resposta depois que ela passou, e por vezes tendem a ficar ressentidos consigo próprios (ALBERT e EMMONS, 2008). O comportamento não assertivo (sentimento de ansiedade, culpa e confusão) não apresentou correlações com o criticismo parental, mostrando que os pais destes árbitros não eram excessivamente críticos sobre os esforços de realização dos mesmos. Assim, não ocorreram correlações estatisticamente significativas em relação ao comportamento não assertivo com criticismo parental $(\mathrm{r}=0,25)$, rejeitando-se a hipótese $\mathrm{H}_{2}$.

A agressividade teve correlação positiva com a preocupação com os erros $(\mathrm{r}=0,31)$, aceitando-se parcialmente a hipótese $\mathrm{H}_{3}$. Os dados ainda mostram que o comportamento não assertivo teve correlação com o desajustamento ( $\mathrm{r}=0,35)$, aceitando-se a hipótese H5. Não houve diferença significativa entre os sexos (Tabela 3 ) nas dimensões de perfeccionismo e assertividade, assim a hipótese $\mathrm{H}_{4}$ foi rejeitada.

\section{Conclusão}

O presente estudo mostrou que o comportamento assertivo prevaleceu no contexto da arbitragem. Destacou-se assim, a relevância das boas condições psicológicas daqueles que têm por responsabilidade julgar as competições esportivas, e tomar decisões de forma leal, de acordo com as regras de cada modalidade. Entretanto, as dimensões de perfeccionismo indicaram que os árbitros que são excessivamente preocupados com os erros podem despertar os comportamentos agressivos e não assertivos.

Estas características podem tender ao desajustamento nas atitudes tomadas durante a função de ser árbitro. Como limitação do estudo, gostaríamos de destacar que o foco do mesmo foi verificar o papel do árbitro e não discutir as diferentes funções que os mesmos desempenham em relação às modalidades da natação e do judô, sendo que a responsabilidade da tomada de decisões é a mesma e muito decisiva, exigindo assertividade e certos níveis de perfeccionismo.

Destaca-se a falta de estudos na área da arbitragem no contexto brasileiro. Estes achados aparecem como subsídio teórico para que os coordenadores e diretores de arbitragem possam entender melhor seu grupo de árbi-

Pensar a Prática, Goiânia, v. 17, n. 3, p. 800-814, jul./set. 2014 
tros e buscar qualificá-los, visando uma preparação adequada para as competições, destacando que o conhecimento técnico não pode ser somente no sentido técnico das regras, mas também deve abranger uma preparação psicológica para a atuação profissional.

Contudo, sugerimos outras pesquisas que auxiliem na atuação e na compreensão dos árbitros que dependem de boas condições físicas e psicológicas para ter uma atuação assertiva no contexto competitivo.

\title{
ASSERTIVE BEHAVIOR AND DIMENSIONS OF PERFECTIONISM OF NATIONAL REFEREES
}

\begin{abstract}
The aim of this study was to investigate the assertiveness and perfectionism of individual modalities referees. A total of 67 referees of state and national level, being 19 of judo and 47 of swimming. The instruments include Assertive Inventory and Multidimensional Perfectionism Scale. For data analysis, were used KolmogorovSmirnov, the "U" Mann-Whitney and ANOVA with repeated measures. Among the referees prevailed the high level of assertive behavior, reflecting perfectionistic traits of organization and standards of personal fulfillment. Assertiveness and organization were observed in the referees, which demonstrated high standards of personal accomplishment in the function they perfo

Keywords: Referees. Behaviors. Swimming. Judo.

\section{CONDUCTAS ASERTIVAS Y DIMENSIONES DEL PERFECCIONISMO DE LOS ÁRBITROS EN EL MARCO NACIONAL}

\section{Resumen}

El objetivo de este estudio fue investigar la asertividad y el perfeccionismo de los árbitros de modalidades individuales. Participaran 67 árbitros de nivel estadual y nacional, siendo 19 del judo y 47 de la natación. Los instrumentos contemplan el Inventário Asertivo y la Escala Multidimensional de Perfeccionismo. Para análisis de los dados fueron utilizados los testes Kolmogorov-Smirnov, el teste " $U$ " de Mann-Whitney y ANOVA de medidas repetidas. Entre los árbitros prevaleció el alto nível de comportamento asertivo, evidenciando características perfeccionistas de organización y patrones de realización personal. La asertividad y la organización fueran evidenciadas en los árbitros, que demonstraran altos patrones de realización personal en la función que ejecutan.

Palabras-claves: Árbitros. Comportamientos. Natación. Judo.

Pensar a Prática, Goiânia, v. 17, n. 3, p. 800-814, jul./set. 2014 


\section{Referências}

ALBERT, R.E.; EMMONS, M. Como se tornar mais confiante e assertivo. Rio de Janeiro: Sextante, 2008.

AMARAL, A.P.M.; et al. Frost Multidimensional Perfectionism Scale: the portuguese version. Rev. psiquiatr. clín., v.40, n.4, p.144-149, 2013.

CRUZ, J.F.A., VARELA, I.; CABANELAS S. Perfeccionismo, Auto-apresentação e Ansiedade na Competição Desportiva e na Prática de Exercício: Estudo Exploratório com Atletas de Competição e Praticantes de Exercício. Actas do VII Simpósio Nacional de Investigação em Psicologia, Portugal, 4 a 6 de Fevereiro de 2010.

CUNHA, V.M.; TOURINHO, E.Z. Assertividade e Autocontrole: interpretação analítico-comportamental. Psicologia: teoria e pesquisa, v.26, n.2, p.295-304, 2010.

DUNN, J.G.H. et al. Establishing construct validity evidence for the Sport Multidimensional Perfectionism Scale. Psychology of Sport and Exercise, v.7, p.57-79, 2006.

FLETT, G.L.; HEWITT, P.L. The Perils of Perfectionism in Sports and Exercise. American Psychological Society, v.14., n.1, p.14-18, 2005.

FROST, R.O. et al. The dimensions of perfectionism. Cognitive therapy \& research, v.14, p.449-468, 1990.

GAMA, A.; et al. Manual do árbitro. Lisboa: Europress, 1998.

GONÇALVES, M.P.; BELO, R.P. Ansiedade-traço competitiva: diferenças quanto ao gênero, faixa etária, experiência em competições e modalidade esportiva em jovens atletas. Psico-USF, Natal, v.12, n.2, p.301-307, 2007.

HINNEN, C. Relationship satisfaction in women: A longitudinal case-control study about the role of breast cancer, personal assertiveness, and partners' relationship focused coping. British Journal of Health Psychology, v.13, p.737-754, 2008.

LEVITAN, M.; RANGÉ, B.; NARDI, A.E. Habilidades sociais na agorafobia e fobia social. Psicologia: Teoria e Pesquisa, v.24, n.1, p.95-100, 2008.

Pensar a Prática, Goiânia, v. 17, n. 3, p. 800-814, jul./set. 2014 
OLIVEIRA, D.F.; et al. Perfeccionismo e representação vinculativa em jovens adultos. Psicologia: Reflexão e Crítica, v.25, n.3, p.514-522, 2004.

PEREIRA, N.F.; SANTOS, R.G.M.; CILLO, E.N.P. de. Arbitragem no futebol de campo: estresse como produto desse controle coercitivo. Rev. bras. psicol. esporte, São Paulo, v.1, n.1, 2007.

PEREIRA, A.J.; ALADASHVILE, G.A.; SILVA, A.I. da. Causas que levam alguns árbitros a desistirem da carreira de árbitro profissional. Rev. da Educação Física/UEM, Maringá, v.17, n.2, p.185-192, 2006.

ROSE JUNIOR, D. A competição como fonte de estresse no esporte. Rev. Bras. Ciên. e Mov., Brasília, v.10, n.4, p.19-26, 2002.

SAGAR, S.S.; STOEBER, J. Perfectionism, fear of failure, and affective responses to success and failure: the central role of fear of experiencing shame and embarrassment. Journal of Sport and Exercise Psychology, v.31, p.602-627, 2009.

SERPA, S.; ALVES, P.; BARREIROS, A. Versão portuguesa da Sport Motivational Scale (SMSp) e da Sport Academic Scale (AMSp): processos de tradução, adaptação e fiabilidade. Lisboa: Laboratório de Psicologia do Desporto - Faculdade de Motricidade Humana - Universidade Técnica de Lisboa, 2004.

SILVA, A.I. da; RODRIGUEZ-AÑEZ, C.R. A freqüência cardíaca e a intensidade da atividade física do árbitro assistente durante a partida de futebol. Rev. da Educação Física/UEM, Maringá, v.14, n.1, p.53-57, 2003.

SILVA, A.I. da; RODRIGUEZ-AÑEZ, C.R.; FRÓMETA, E.R. O árbitro de futebol - uma abordagem histórico-crítica Rev. da Educação Física/UEM, Maringá, v.13, n.1, p.39-45, 2002.

SILVA, A.I. da; RECH, C.R. Somatotipo e composição corporal de árbitros e árbitros assistentes da CBF. Rev. Bras. Cineantropom. Desempenho Hum., Florianópolis, v.10, n.2, p.143-148, 2008.

STIRLING, A.E.; KERR, G.A. Perfectionism and Mood States Among Recreational and Elite Athletes. Athletic Insight, v.8, n.1, p.13-27, 2006. 
Recebido em: 07/07/2014

Revisado em: 05/08/2014

Aprovado em: 14/08/2014

Endereço para correspondência:

registhon@ hotmail.com

Regina Alves Thon

Universidade Estadual de Maringá, Departamento de Educação Física/UEM.

Avenida Colombo 5790

Jardim Universitário

85015430 - Maringá, PR - Brasil

Pensar a Prática, Goiânia, v. 17, n. 3, p. 800-814, jul./set. 2014 